\title{
The Impact of Comorbid Diseases on Postoperative Complications in Children after Adenotonsillectomy: Is It a Myth?
}

\author{
Original Investigation Uygar Levent Demir (1), Hakkı Caner İnan \\ Department of Otolaryngology, Uludağ University School of Medicine, Bursa, Turkey
}

Abstract

ORCID iDs of the authors: U.L.D. 0000-0002-9590-1420 H.C.I. $0000-0001-6254-372 X$

Cite this article as: Demir UL, Inan HC. The Impact of Comorbid Diseases on Postoperative Complications in Children after Adenotonsillectomy: Is It a Myth?. Turk Arch Otorhinolaryngol 2020; 58(3): 141-8

Corresponding Author: Uygar Levent Demir, uygardemir@hotmail.com Received Date: 12.05 .2020 Accepted Date: 29.06 .2020

Content of this journal is licensed under a Creative Commons Attribution 4.0 International License. Available online at www.turkarchotolaryngol.net
Objective: Adenotonsillar surgery remains the second most common surgical practice in pediatric otolaryngology. We aimed to evaluate whether a comorbid disease in children undergoing surgery has any impact on postoperative complication rate.

Methods: This study was conducted at a tertiary otolaryngology department with 643 children. The study included children with symptoms of obstructive sleep-disordered breathing and recurrent infection who underwent adenotonsillar surgery. Patients with a comorbid disease constituted the study group and otherwise healthy children constituted the control group. The data were evaluated to find out any association among clinical variables such as gender, age, tonsil grade, type and extent of surgery, indication for surgery, body mass index percentile, comorbid diseases and postoperative complications.

Results: There were 245 (38.1\%) patients with a comorbid disease. The most common comorbidity was cardiovascular diseases $(n=68)$ followed by neurological diseases $(n=48)$. We performed adenoidecto- my in 319 , tonsillectomy in 44, tonsillotomy in nine, adenotonsillectomy (AT) in 190 and adenoidectomy with tonsillotomy (ATT) in 81 patients. The overall rate of postoperative late complication was $17 / 643$ (2.6\%) with post-tonsillectomy hemorrhage being the most common $(n=10)$. There was no association between other clinical variables and the complication but older age $(p=0.042)$ and type of surgery $(p<0.001)$ revealed increased risk. The rates of complications in patients with or without comorbid disease were found $5 / 245(2 \%)$ and $12 / 389$ (3\%), respectively, with no difference $(\mathrm{p}=0.621)$.

Conclusion: The risk of postoperative complications was increased in older children and in patients undergoing AT and ATT, however, the presence of comorbid disease did not increase likelihood of postoperative complications.

Keywords: Adenoidectomy, adenotonsillectomy, tonsillotomy, comorbid disease, complication, post-tonsillectomy hemorrhage

\section{Introduction}

Tonsillectomy (T) and adenoidectomy (A) are the two most common ambulatory surgical procedures performed in children aged $<15$ years after myringotomy with tube insertion (1). Although there are two generally accepted indications for $\mathrm{T}$ and A, namely, recurrent infection and obstructive hyperplasia, some other well documented indications are also stated in the literature (2-4). When performed with the appropriate indication and technique, this surgery is considered a safe procedure that provides better quality of life to patients. Although adenotonsillectomy (AT) is a simple procedure, it still has some potential risks for postoperative complications. Post-tonsillectomy hemorrhage (PTH), infection and poor oral intake with emesis are the most common non-respiratory postoperative complications encountered after AT $(5,6)$. Among these complications $\mathrm{PTH}$ is the most common cause of morbidity that can be potentially life-threatening. The incidence of PTH was reported as 2-5\% (7-9) in pediatric AT cohort studies.

Since the overall postoperative complication rates are relatively high and reported higher than $6 \%(5,6)$, many previous studies attempted to find out the possible risk factors which may 
predispose to these complications. In previous studies many comorbid conditions and diseases were found to have association with increased postoperative complication rates such as increased age $(7,8)$, neuropsychiatric disease $(6,8,10)$, severe obstructive sleep apnea syndrome (OSAS) (5), hypertension (6), coagulopathy $(6,11)$, metabolic disease $(6,14)$, syndromic children with craniofacial anomaly (12-15), neuromuscular disorder $(14,15)$, obesity $(7,16)$ or chronic pulmonary disease $(6,17)$. The existence of any of these risk factors in a child usually raises the concerns of our colleagues and there might be a tendency toward referral of these children to tertiary centers for surgery. On the contrary, some other articles pointed out that these comorbid conditions have no effect on postoperative complications (18-20).

However, little is known about the association between comorbid conditions and risk of late postoperative complications in children. In this study, we aimed to retrospectively evaluate whether the existence of any comorbid disease in a child undergoing to A, T, TT (tonsillotomy), AT, ATT (adenoidectomy with tonsillotomy) has any adverse impact on postoperative healing and influence the postoperative complication rate. The surgical outcomes of a single tertiary level otolaryngology practice were analyzed with surgery having been performed by same surgical team using similar techniques and instruments.

\section{Methods}

In this study, we retrospectively reviewed the data of patients under 18 years of age who underwent A, T, TT, AT or ATT with or without ventilation tube insertion at the department of Otolaryngology and Head Neck Surgery, Uludağ University, Bursa. The study was conducted from January 2015 through December 2019 with 643 patients, of whom 245 were diagnosed with a comorbid disease. Children with a comorbid disease constituted the study group $(n=245)$ and otherwise relatively healthy children $(n=398)$ constituted the control group. Clinical information of patients were retrieved from their medical reports stored in the digital database of the hospital. Tonsil and adenoid gradings were made at the outpatient clinic before surgery by oral examination and fiberoptic nasopharyngeal endoscopy. Tonsils occupying $<25 \%$ of the lateral dimension of the oropharynx as measured between the anterior tonsillar pillars were classified as Grade 1; tonsils occupying $25-50 \%$ of the lateral dimension of the oropharynx as Grade 2 ; tonsils occupying $50-75 \%$ of the lateral dimension of the

\section{Main Points}

- Post tonsillectomy hemorrhage is the most common late complication among children undergoing adenotonsillar surgery.

- Older age and type of surgery increase the risk of postoperative complications, whereas obesity, extent of tonsillectomy, tonsil grade and indication for surgery do not.

- The rates of postoperative complications in children with or without comorbid disease were similar with no statistical difference. oropharynx as Grade 3; and tonsils occupying $>75 \%$ of the lateral dimension of the oropharynx were classified as Grade 4. Adenoids were categorized into four groups as Grade 1, adenoid tissue obstructing $0 \%$ to $25 \%$ of posterior choana; Grade 2, adenoid tissue obstructing $26 \%$ to $50 \%$ of posterior choana; Grade 3, adenoid tissue obstructing $51 \%$ to $75 \%$ of posterior choana; and Grade 4, adenoid tissue obstructing $76 \%$ to $100 \%$ of posterior choana.

The indications for adenoidectomy and tonsillectomy were determined according to the clinical practice guidelines developed by the American Academy of Otolaryngology-Head and Neck Surgery Foundation $(3,21)$. The hematological parameters such as CBC, PT and aPTT were only ordered in patients with a known or suspected hematological disorder or coagulopathy. Adenoidectomies were performed by transoral route using adenoid curettes and all total tonsillectomies were extracapsular dissections performed by bipolar electrocautery. Partial tonsillectomies (tonsillotomy) were done using monopolar electrocautery removing at least $50 \%$ of the tonsil tissue and preserving the lateral tonsillar capsule intact. The patients were discharged the day after the surgery, if no early complications were encountered, with a prescription of paracetamol and amoxicillin with clavulanic acid based upon weight for five days.

The data obtained from the patient files were assessed for further analysis and the variables such as gender, age, tonsil and adenoid grades, type of surgery (A, T, TT, AT or ATT), tube insertion, extent of tonsil removal (total vs partial), indication for procedure (infection, obstruction or infection/obstruction), body mass index percentile (BMI), comorbid disease, postoperative clinical course, readmission, late postoperative complication (PTH and poor oral intake with dehydration) were all documented. We further divided patients into two groups as those with and those without a comorbid disease. Subsequently, we compared the two groups in terms of clinical variables and surgical outcomes. Informed consent forms had been obtained from the parents of children at initial visit prior to treatment and the institutional review board of Uludağ University School of Medicine approved this retrospective study (Approval Date: April 15, 2020; Approval Number: 2020-6/28).

\section{Statistical Analysis}

The statistical analyses were done with IBM Statistical Package for the Social Sciences software for Windows version 22.0 (IBM SPSS Corp.; Armonk, NY, USA). The Pearson chisquare test, Fisher's exact test and Fisher-Freeman-Halton test were used in analyses and the variables were shown as percentage (\%). A significance value of 0.05 was used for all tests.

\section{Results}

Over the five-year study period, a total of consecutive $643 \mathrm{pa}-$ tients (366 males and 277 females) with a mean age of 5.9 years that underwent adenotonsillar surgery were included. Age subgroups and types of surgeries are given in Table 1. The number of patients who had myringotomy and ventilation 
Table 1. Characteristics of patients

\begin{tabular}{|c|c|c|c|}
\hline Characteristic & Subgroups & Number & $\%$ \\
\hline \multirow[t]{5}{*}{ Age } & $\leq 2$ & 51 & 7.9 \\
\hline & $2-4$ & 200 & 31.1 \\
\hline & $4-6$ & 196 & 30.5 \\
\hline & $6-10$ & 141 & 21.9 \\
\hline & $10-18$ & 55 & 8.5 \\
\hline \multirow[t]{2}{*}{ Gender } & Female & 277 & 43.1 \\
\hline & Male & 366 & 56.9 \\
\hline \multirow[t]{5}{*}{ Type of surgery } & Adenoidectomy & 319 & 49.6 \\
\hline & Tonsillectomy & 44 & 6.8 \\
\hline & Tonsillotomy & 9 & 1.4 \\
\hline & Adenotonsillectomy & 190 & 29.5 \\
\hline & Adenotonsillotomy & 81 & 12.6 \\
\hline \multirow[t]{4}{*}{ Indication for surgery } & Obstruction & 290 & 45.1 \\
\hline & Recurrent infection & 277 & 43.1 \\
\hline & Obs./infect. & 72 & 11.1 \\
\hline & Tonsil asymmetry & 4 & 0.6 \\
\hline \multirow[t]{2}{*}{ Ventilation tube } & Yes & 439 & 68.2 \\
\hline & No & 204 & 31.7 \\
\hline \multirow[t]{4}{*}{ Tonsil grade } & 1 & 189 & 29.4 \\
\hline & 2 & 145 & 22.5 \\
\hline & 3 & 211 & 32.8 \\
\hline & 4 & 98 & 15.2 \\
\hline \multirow[t]{4}{*}{ Adenoid grade } & 1 & 47 & 7.3 \\
\hline & 2 & 49 & 7.6 \\
\hline & 3 & 298 & 46.3 \\
\hline & 4 & 249 & 38.7 \\
\hline \multirow[t]{3}{*}{ BMI (\%) } & Obese $\left(\geq 95^{\text {th }} B M I\right)$ & 88 & 13.7 \\
\hline & Underweight $\left(\leq 5^{\text {th }} \mathrm{BMI}\right)$ & 70 & 10.9 \\
\hline & Normal & 485 & 75.4 \\
\hline \multirow[t]{2}{*}{ Comorbid disease } & Yes & 245 & 38.1 \\
\hline & No & 398 & 61.9 \\
\hline \multirow[t]{2}{*}{ Postoperative complication } & Yes & 17 & 2.6 \\
\hline & No & 626 & 97.3 \\
\hline Total & & 643 & 100 \\
\hline
\end{tabular}

tube insertion simultaneously with primary surgery (A, T/TT, AT/ATT groups) were found as 151/319 (47.3\%), 2/53 (3.7\%) and 51/271 (18.8\%), respectively.

At admission, the most common indication for surgery was sleep-disordered breathing/sleep apnea, 45.1\% (290/643). In four patients, tonsillectomy was performed for the pathological assessment of asymmetric tonsil hypertrophy (Table 1). The data obtained from documents revealed that the mean tonsil grade in T, TT, AT and ATT patients was 3.15 and the mean adenoid grade in patients who had A, AT and ATT was 3.33. BMI percentiles were calculated after retrieving the weight and height of the patients from the patient files and 70 chil- dren $(10.9 \%)$ were found to be underweight $(\mathrm{BMI} \% \leq 5)$ and 88 children $(13.7 \%)$ obese (BMI \% 295) (Table 1).

There were various comorbid conditions, mainly categorized into 15 subgroups (Table 2), and among all population $398 \mathrm{had}$ no major comorbidities, but the remainder 245 (38.1\%) were diagnosed with established risk factors for postoperative complications. The most common comorbidity was cardiovascular diseases in 68 children. Neurological diseases $(n=48)$, chronic pulmonary diseases $(n=24)$ and Down syndrome $(n=21)$ were the other frequent comorbid conditions identified in the study population. The two main late complications assessed in the study were PTH and poor oral intake with dehydration. In the study population the overall rate of postoperative late complication was found $17 / 643(2.6 \%)$ and late PTH was the most common complication in 10 patients. There was no early PTH noted and the mean day of readmission with bleeding was 7.2 days (range, 2 to 10 days). Only two of these patients underwent reoperation for hemostasis. No patient had an early major respiratory problem. Six patients, however, were followed-up closely at the intensive care unit for one night and discharged the next day problem-free. We had postoperative mortality in one patient who had metabolic storage disease with hydrocephalus and was diagnosed with pericarditis and encephalitis at postoperative third week.

We then subdivided the population into two subgroups as those with a comorbid disease (wCMD) and those without a comorbid disease (woCMD). There was no difference between these two groups in terms of any other clinical variables (Table 3). And finally, we evaluated the association between clinical variables (age subgroups, gender, type of surgery, extent of tonsillectomy, tonsil grade, BMI percentiles, indication for surgery, and comorbid disease) and postoperative complication. There were no significant associations among gender, indication for surgery, tonsil grade, extend of tonsillectomy, BMI percentile and complication rate. There was, however, significance $(\mathrm{p}=0.042)$ between age subgroups and complications. We found that the rate of complications was significantly higher in patients between aged 10-18 years compared to the patients in the 2-4 and 4-6 age groups ( $\mathrm{p}=0.013, \mathrm{p}=0.026$, respectively). The complication risk showed significant increase with $\mathrm{T}$ and AT compared to A ( $\mathrm{p}<0.001, \mathrm{p}=0.016$, respectively). Moreover, adenoidectomy in addition to tonsillectomy/tonsillotomy was found to be of higher risk compared to tonsillectomy alone $(\mathrm{p}=0.006, \mathrm{p}=0.003)$. As an independent risk factor, having a comorbid disease showed no association with increased risk for postoperative complication ( $\mathrm{p}=0.621)$ (Table 4).

\section{Discussion}

The removal of adenoid and tonsil tissues with or without myringotomy remains the most common surgical procedure in pediatric otolaryngology practice with a shift of indications from infectious to obstructive reasons during the past few decades (22). Despite the evolution of various surgical instruments and safe techniques used in this surgery, the risk for postoperative 
Demir and İnan.

Table 2. Patients by type of comorbidity and type of surgery

\begin{tabular}{|c|c|c|c|c|c|c|}
\hline Comorbid disease & A & $\mathrm{T}$ & $\mathrm{TT}$ & AT & ATT & Total \\
\hline Metabolic and storage & 2 & - & - & 1 & 1 & 4 \\
\hline Skeleton system & 5 & 1 & - & 1 & 1 & 8 \\
\hline Other syndromes & 4 & - & - & 5 & 5 & 14 \\
\hline Hematologic-immunologic & 7 & - & - & 6 & - & 13 \\
\hline Cardiovascular & 36 & 2 & 1 & 22 & 7 & 68 \\
\hline Neurological & 20 & 2 & 4 & 15 & 7 & 48 \\
\hline Down syndrome & 8 & 1 & - & 10 & 2 & 21 \\
\hline Malignancy & 2 & - & - & 3 & 1 & 6 \\
\hline Psychiatric & 1 & 1 & - & 1 & 3 & 6 \\
\hline Organ transplant & 2 & - & - & 2 & - & 4 \\
\hline Allergy to anesthetics & - & - & - & 1 & - & 1 \\
\hline Total & 109 & 13 & 6 & 83 & 34 & 245 \\
\hline
\end{tabular}

A: adenoidectomy; T: tonsillectomy; TT: tonsillotomy; AT: adenotonsillectomy; ATT: adenoidectomy with tonsillotomy

complications still persists. These potentially include non-respiratory complications such as PTH, poor oral intake with dehydration or pain, and respiratory complications such as hypoxemia, hypercapnia, laryngospasm or pulmonary edema which may require respiratory support (5). It is not easy to predict the possibility of any complication after AT in otherwise healthy children without any comorbid disease. There are, however, some well-known high-risk patients for postoperative complications with certain comorbid conditions such as obesity $(7,16)$, severe OSAS $(23)$, syndromic with craniofacial anomaly (12-15), cardiovascular disorders (6), neuropsychiatric problems $(6,8,10)$, and coagulation disorders $(6,11)$. Any child with the above-mentioned comorbid conditions is considered in the high risk group in terms of perioperative complications and is usually referred to a tertiary otolaryngology clinic immediately by our colleagues. They assume that these patients are more prone to postoperative problems compared to normal children. In this study, we aimed to find out whether these concerns are realistic in everyday otolaryngology practice and whether these complications can be prevented with simple perioperative measures.

Age had impact on both respiratory and non-respiratory complications. Some studies reported adolescence to be a risk factor especially for PTH, while others reported that children under three years of age experienced early postoperative complications more significantly compared to older patients $(8,16$, 18). Allareddy et al. (6) reported that patients younger than 3 years of age (particularly $<1$ year) were at a higher risk of respiratory complications and postoperative pneumonia. Similarly, in the study of Thongyam et al. (5) a significant association $(\mathrm{p}=0.003)$ was found between respiratory, but not non-respiratory, complications and being younger than three years of age. On the contrary, older age was reported as a risk factor for PTH in other studies. Burckardt et al. (7) reported that children in highest age quartile were at increased risk for PTH. In another study the authors found that children 11 years of age and older had double risk of bleeding with 1.1 times increase at risk for every increase in age by one year (8). Kshirsagar et al. (16), too, pointed out that PTH increased with age and was associated with an age from 9 to 18 years $(p=0.01)$. Our study finding that postoperative complication rate significantly increased with age (10-18 years) is consistent with the reports of previous studies. Since adults have more PTH compared to children (24) and adolescence is a transition period from childhood to adulthood, we assume that increased PTH rate in older children is the result of this transition to that risk of an adult.

Obesity was assessed in the literature by using BMI as an important parameter to predict the children who are likely to experience perioperative complications. But there is no agreement that obesity is a significant risk factor. Some authors report to have found no association between obesity and complications $(5,8,15,18)$. Our findings were also similar, with no relation between obesity and postoperative complication $(\mathrm{p}=0.442)$. One study (6) reported that obesity did not have any impact on any complication, except postoperative pneumonia. Many other studies, however, report significant association between obesity and postoperative complications. In the study of Burckardt et al. (7), a BMI z-score of 2 or greater was found to be a significant risk factor for PTH ( $\mathrm{p}=0.003)$. In the study of Kshirsagar et al. (16), multivariate analysis revealed that hemorrhage was about 2.3 times more likely to occur in obese children. In addition, Tweedie et al. (14) reported a significantly higher chance of pediatric intensive care unit admission in obese children. 
Table 3. Characteristics of patients with or without a comorbid disease

\begin{tabular}{|c|c|c|c|}
\hline Characteristic & wCMD (n=245) & woCMD $(n=398)$ & $\mathrm{p}$ \\
\hline \multicolumn{4}{|l|}{ Age subgroups } \\
\hline$\leq 2$ & $18(7.3 \%)$ & $33(8.3 \%)$ & \multirow[t]{5}{*}{0.147} \\
\hline $2-4$ & $78(31.8 \%)$ & $122(30.7 \%)$ & \\
\hline $4-6$ & $82(33 . \% 5)$ & $114(28.6 \%)$ & \\
\hline $6-10$ & $42(17.1 \%)$ & $99(24.9 \%)$ & \\
\hline $10-18$ & $25(10.2 \%)$ & $30(7.5 \%)$ & \\
\hline \multicolumn{3}{|l|}{ Gender } & \multirow{3}{*}{0.465} \\
\hline Female & $110(44.9 \%)$ & $167(42 \%)$ & \\
\hline Male & $135(55.1 \%)$ & $231(58 \%)$ & \\
\hline \multicolumn{3}{|l|}{ Type of surgery } & \multirow{4}{*}{0.076} \\
\hline Adenoidectomy & $109(44.5 \%)$ & $210(52.8 \%)$ & \\
\hline $\mathrm{T} / \mathrm{TT}$ & $19(7.7 \%)$ & $34(8.5 \%)$ & \\
\hline AT/ATT & $117(47.8 \%)$ & $154(38.7 \%)$ & \\
\hline \multicolumn{3}{|l|}{ Tonsil grade } & \multirow{5}{*}{0.081} \\
\hline 1 & $59(24.1 \%)$ & $130(32.7 \%)$ & \\
\hline 2 & $54(22 \%)$ & $91(22.9 \%)$ & \\
\hline 3 & $89(36.3 \%)$ & $122(30.7 \%)$ & \\
\hline 4 & $43(17.6 \%)$ & $55(13.8 \%)$ & \\
\hline \multicolumn{3}{|l|}{ Adenoid grade } & \multirow{6}{*}{0.877} \\
\hline 1 & $19(7.7 \%)$ & $28(7 \%)$ & \\
\hline 2 & $21(8.6 \%)$ & $28(7 \%)$ & \\
\hline 3 & $111(45.3 \%)$ & $187(47 \%)$ & \\
\hline 4 & $94(38.4 \%)$ & $155(38.9 \%)$ & \\
\hline \multicolumn{3}{|l|}{ BMI } & \\
\hline Obese $\left(\geq 95^{\text {th }} \mathrm{BMI}\right)$ & $35(14.3 \%)$ & $53(13.3 \%)$ & \multirow[t]{3}{*}{0.614} \\
\hline Underweight $\left(\leq 5^{\text {th }} \mathrm{BMI}\right)$ & $30(12.2 \%)$ & $40(10.1 \%)$ & \\
\hline Normal & $180(73.5 \%)$ & $305(76.6 \%)$ & \\
\hline \multicolumn{3}{|l|}{ Indication for surgery } & \multirow{5}{*}{0.921} \\
\hline Obstruction & $114(46.5 \%)$ & $176(44.2 \%)$ & \\
\hline Recurrent infection & $104(42.4 \%)$ & $173(43.5 \%)$ & \\
\hline Obs./infect. & $26(10.6 \%)$ & $46(11.6 \%)$ & \\
\hline Tonsil asymmetry & $1(0.4 \%)$ & $3(0.7 \%)$ & \\
\hline Total & 245 & 398 & 643 \\
\hline \multicolumn{4}{|c|}{$\begin{array}{l}\text { wCMD: with comorbid disease; woCMD: without comorbid disease; A: adenoidectomy; } \\
\text { T: tonsillectomy; TT: tonsillotomy; AT: adenotonsillectomy; ATT: adenoidectomy with } \\
\text { tonsillotomy }\end{array}$} \\
\hline
\end{tabular}

Otherwise low body weight is another significant risk factor for early postoperative complications, especially respiratory (20). There are few assumptions why obese children are more prone to PTH: 1- obesity itself is a proinflammatory condition which leads to coagulation problems, 2 - these children may develop diabetes mellitus, hypertension or some metabolic disorders more frequently and therefore need to start on high volume oral intake much earlier than planned (7).

The two common indications for surgery in children, obstructive sleep-disordered breathing and recurrent throat infec- tion, were reviewed to investigate whether or not they have any influence on PTH. Almost all authors reported that $\mathrm{pa}^{-}$ tients who underwent surgery with the indication of recurrent tonsillitis had increased risk for PTH compared to those with other indications. Spektor et al. (8) reported that these patients had 4.5 times greater risk of experiencing PTH than those with any other indications. In the study of Francis et al. (9) children who underwent $T$ for obstructive sleep-disordered breathing had lower rates of PTH than those whose indication was recurrent infection independent from any surgical technique and extent of tonsillectomy. The cause and effect relationship between PTH and history of recurrent adenotonsillar infection was based on two suggestions: 1) existence of chronic inflammatory process which increases the vascularity around lymphoid tissues, and 2) difficulty in pericapsular dissection at clear planes due to fibrosis (9). In one study, there was lower risk of PTH in children undergoing surgery for tonsillar hypertrophy than those with OSA (7). However, the authors did not mention whether or not those with tonsillar hypertrophy also had concurrent sleep disordered breathing, an aspect that can be considered a flaw of the referred study. In our study, we did not identify any association between complication and indication of the surgery.

The impact of the extent of the tonsillectomy procedure-partial (tonsillotomy or intracapsular) vs total (tonsillectomy or subcapsular) —on PTH has been discussed in several studies. These studies reached near consensus that total tonsillectomy increased the risk of PTH compared to partial resection. Burckardt et al. (7) reported significant increase in PTH after subcapsular resection compared to intracapsular $(\mathrm{p}=0.026)$. Similarly, Vicini et al. (25) report that intracapsular resection showed a lower rate of bleeding compared to conventional extracapsular resection $(\mathrm{p}<0.01)$. In a systematic review article by Zhang et al. (26), which assessed 32 related studies, tonsillotomy was found to reduce the odds of a secondary haemorrhage by $79 \%$. Hultcrantz et al. (27) reported significant decrease in late PTH after tonsillotomy compared to tonsillectomy $(\mathrm{p}<0.0001)$. On the contrary, in the study of Francis et al. (9) the authors reported that PTH associated with both approaches were less than $4 \%$ for any surgical technique with no favor towards partial tonsillectomy. They also argued that the risk-benefit ratio regarding regrowth of residual tonsil tissue and reinfection should be considered before determining the surgical extent. Performing adenoidectomy with tonsillectomy also added further risk of PTH compared to tonsillectomy alone (6). We preferred tonsillotomy only if the patient had grade 3 to 4 obstructive tonsils without a history of recurrent tonsillitis. In presented study, we found no difference between $\mathrm{T}$ and TT. However, performing adenoidectomy additional to $\mathrm{T}$ or TT increased the complication risk significantly $(\mathrm{p}=0.006$, $\mathrm{p}=0.003$, respectively).

There are only few articles in the literature that addressed the higher risk in children with certain comorbid diseases undergoing AT, while other studies focused on only relatively 
Demir and İnan.

Table 4. Associations between clinical variables and complications

\begin{tabular}{|c|c|c|c|c|}
\hline Clinical variable & Subgroups & With complication & Without complication & $\mathrm{p}$ \\
\hline \multirow[t]{5}{*}{ Age } & $\leq 2$ & $0(0 \%)$ & $51(8.1 \%)$ & \multirow[t]{5}{*}{0.042} \\
\hline & $2-4$ & $3(17.6 \%)$ & $197(31.5 \%)$ & \\
\hline & $4-6$ & $4(23.5 \%)$ & $192(30.7 \%)$ & \\
\hline & $6-10$ & $5(29.4 \%)$ & $136(21.7 \%)$ & \\
\hline & $10-18$ & $5(29.4 \%)$ & $50(8 \%)$ & \\
\hline \multirow[t]{2}{*}{ Gender } & Female & $9(52.9 \%)$ & $268(42.8 \%)$ & \multirow[t]{2}{*}{0.559} \\
\hline & Male & $8(47.1 \%)$ & $358(57.2 \%)$ & \\
\hline \multirow[t]{5}{*}{ Type of surgery } & Adenoidectomy & $2(11.8 \%)$ & $317(50.6 \%)$ & \multirow[t]{5}{*}{$<0.001$} \\
\hline & Tonsillectomy & $7(41.1 \%)$ & $37(5.9 \%)$ & \\
\hline & Tonsillotomy & $0(0 \%)$ & $9(1.4 \%)$ & \\
\hline & Adenotonsillectomy & $7(41.2 \%)$ & $183(29.2 \%)$ & \\
\hline & Adenotonsillotomy & $1(5.9 \%)$ & $80(12.8 \%)$ & \\
\hline \multirow[t]{4}{*}{ Indication for surgery } & Obstruction & $5(29.4 \%)$ & $285(45.5 \%)$ & \multirow[t]{4}{*}{0.386} \\
\hline & Recurrent infection & $9(52.9 \%)$ & $268(42.8 \%)$ & \\
\hline & Obs./infect. & $3(17.6 \%)$ & $69(11 \%)$ & \\
\hline & Tonsil asymmetry & $0(0 \%)$ & $4(0.6 \%)$ & \\
\hline \multirow[t]{4}{*}{ Tonsil grade (among T, TT, AT, ATT n=324) } & 1 & $1(6.7 \%)$ & $3(1 \%)$ & \multirow[t]{4}{*}{0.197} \\
\hline & 2 & $1(6.7 \%)$ & $36(11.6 \%)$ & \\
\hline & 3 & $7(46.6 \%)$ & $181(58.6 \%)$ & \\
\hline & 4 & $6(40.0 \%)$ & $89(28.8 \%)$ & \\
\hline \multirow[t]{2}{*}{ Partial/total tonsillectomy $(n=324)$} & Tonsillotomy/adenotonsillotomy & $1(6.7 \%)$ & $89(28.8 \%)$ & \multirow[t]{2}{*}{0.077} \\
\hline & Tonsillectomy/adenotonsillectomy & $14(93.3 \%)$ & $220(71.2 \%)$ & \\
\hline \multirow[t]{3}{*}{ BMI } & Obese $\left(\geq 95^{\text {th }} B M I\right)$ & $3(17.6 \%)$ & $85(13.6 \%)$ & \multirow[t]{3}{*}{0.442} \\
\hline & Underweight ( $\left.\leq 5^{\text {th }} \% \mathrm{BMI}\right)$ & $3(17.6 \%)$ & $67(10.7 \%)$ & \\
\hline & Normal & $11(64.7 \%)$ & $474(75.7 \%)$ & \\
\hline \multirow[t]{2}{*}{ Comorbid disease } & Yes & $5(29.4 \%)$ & $240(38.3 \%)$ & \multirow[t]{2}{*}{0.621} \\
\hline & No & $12(70.6 \%)$ & $386(61.7 \%)$ & \\
\hline
\end{tabular}

A: adenoidectomy; T: tonsillectomy; TT: tonsillotomy; AT: adenotonsillectomy; ATT: adenoidectomy with tonsillotomy; BMI: body mass index

healthy children $(6,14,17)$. These children with comorbid diseases were mostly admitted to tertiary medical centers to undergo AT since they might need higher intensity of care, longer length of stay and intensive care unit admission. Thus, it is of paramount importance to identify such high-risk children prior to surgery and to devise an appropriate management strategy. Presence of any comorbidity such as anemia, chronic pulmonary disease, coagulopathy, hypertension, neurological disorder and fluid/electrolyte disorder were all found to be independent predictors of higher complication risk (6). In a cohort study from the UK the authors mentioned that children with Down Syndrome, cardiac disease, obesity, cerebral palsy, craniofacial anomalies, mucopolysaccharidoses and hemoglobinopathy were significantly more likely to be admitted to the intensive care unit (14). Moreover, almost half of these admissions were unexpected due to postoperative complications. The presence of a neurological disease in a child undergoing AT was also found to increase the need for intensive care support (15). Gehrke et al. (20) reported that children with pre-existing craniofacial or syndro- mal disorders had more complications during or after surgery $(\mathrm{p}<0.001)$. In another study, asthma, epilepsy and congenital cardiac problems as comorbid diseases were found to be risk factors for respiratory complications (17). Krishna and Lee (28) reported differences between the PTH rates of patients with abnormal coagulation profiles (8.7\%) and normal coagulation profiles (3.3\%), albeit not of significance. Attention deficit hyperactivity disorder was also reported to increase the PTH risk by 8.7 times $(\mathrm{p}=0.029)$ (8). Children with Down Syndrome had a significant increase in postoperative hemorrhage compared to those without Down Syndrome $(p=0.024)(12)$. All these studies pointed out that there are various comorbid diseases that affect the postoperative period after AT. It is, however, beyond the scope of this report to investigate the underlying mechanisms of each disease that affect postoperative healing. In our study, we did not find any difference with regard to the complications between children with or without a comorbid disease. We suggest that future studies with larger populations may help to identify any comorbid disease specific for increased risk. 


\section{Conclusion}

This cohort study revealed that the presence of a comorbid disease is not associated with increased risk of complication in children after adenotonsillar surgery. Some factors, however, either related to the patient, like older age, or to the type of surgery had certain impacts on the postoperative healing period. We may conclude that patients with a comorbid disease do not have increased likelihood of perioperative complications if preoperative counseling and postoperative care are given appropriately. The adenotonsillar surgery in children with a comorbid disease can be safely and successfully performed by colleagues at secondary level otolaryngology clinics.

Ethics Committee Approval: Ethics committee approval was received for this study from the Institutional Review Board of Uludağ University School of Medicine (Approval Date: April 15, 2020; Approval Number: 2020-6/28).

Informed Consent: Informed consent was obtained from the parents of the patients who participated in this study.

Peer-review: Externally peer-reviewed.

Author Contributions: Concept - U.L.D., H.C.I.; Design - U.L.D., H.C.I.; Supervision - U.L.D., H.C.I.; Resources: H.C.I.; Materials H.C.I.; Data Collection and/or Processing - H.C.I.; Analysis and/or Interpretation - U.L.D., H.C.I.; Literature Search - U.L.D., H.C.İ.; Writing - U.L.D., H.C.İ.; Critical Reviews - U.L.D., H.C.İ.

Conflict of Interest: The authors have no conflicts of interest to declare.

Financial Disclosure: The authors declared that this study has received no financial support.

\section{References}

1. Cullen KA, Hall MJ, Golosinskiy A. Ambulatory surgery in the United States, 2006. Natl Health Stat Rep: 2009. Report No: 11.

2. Darrow DH, Siemens C. Indications for tonsillectomy and adenoidectomy. Laryngoscope 2002; 112: 6-10. [Crossref]

3. Schupper AJ, Nation J, Pransky S. Adenoidectomy in children: what is the evidence and what is its role? Curr Otorhinolaryngol Rep 2018; 6: 64-73. [Crossref]

4. Mitchell RB, Archer SM, Ishman SL, Rosenfeld RM, Coles S, Finestone SA, et al. Clinical practice guideline: tonsillectomy in children (update)- executive summary. Otolaryngol Head Neck Surg 2019; 160: 187-205. [Crossref]

5. Thongyam A, Marcus CL, Lockman JL, Cornaglia MA, Caroff A, Gallagher PR, et al. Predictors of perioperative complications in higher risk children after adenotonsillectomy for obstructive sleep apnea: a prospective study. Otolaryngol Head Neck Surg 2014; 151: 1046-54. [Crossref]

6. Allareddy V, Martinez-Schlurmann N, Rampa S, Nalliah RP, Lidsky KB, Allareddy V, et al. Predictors of complications of tonsillectomy with or without adenoidectomy in hospitalized children and adolescents in the United States, 2001-2010: a population-based study. Clin Pediatr (Phila) 2016; 55: 593602. [Crossref]
7. Burckardt E, Rebholz W, Allen S, Cash E, Goldman J. Predictors for hemorrhage following pediatric adenotonsillectomy. Int J Pediatr Otorhinolaryngol 2019; 117: 143-7. [Crossref]

8. Spektor Z, Saint-Victor S, Kay DJ, Mandell DL. Risk factors for pediatric post-tonsillectomy hemorrhage. Int J Pediatr Otorhinolaryngol 2016; 84:151-5. [Crossref]

9. Francis DO, Fonnesbeck C, Sathe N, McPheeters M, Krishnaswami S, Chinnadurai S. Postoperative bleeding and associated utilization following tonsillectomy in children: a systematic review and meta-analysis. Otolaryngol Head Neck Surg 2017; 156: 442-55. [Crossref]

10. Kou YF, Wang C, Shah GB, Mitchell RB, Johnson RF. Tonsillectomy outcomes among children with mental health disorders in the United States. Otolaryngol Head Neck Surg 2020; 162: 754-60. [Crossref]

11. Bitar M, Dunya G, Khalifee E, Muwakkit S, Barazi R. Risk of post-operative hemorrhage after adenoidectomy and tonsillectomy: value of the preoperative determination of partial thromboplastin time and prothrombin time. Int J Pediatr Otorhinolaryngol 2019; 116: 62-4. [Crossref]

12. Baker AB, Farhood Z, Brandstetter KA, Teufel RJ 2nd, LaRosa A, White DR. Tonsillectomy in children with Down Syndrome: a national cohort of inpatients. Otolaryngol Head Neck Surg 2017; 157: 499-503. [Crossref]

13. Aydın E, Türkoğlu Babakurban S. The importance and place of adenotonsillectomy in syndromic children. Turk Arch Otorhinolaryngol 2015; 53: 163-7. [Crossref]

14. Tweedie DJ, Bajaj Y, Ifeacho SN, Jonas NE, Jephson CG, Cochrane LA, et al. Peri-operative complications after adenotonsillectomy in a UK pediatric tertiary referral centre. Int J Pediatr Otorhinolaryngol 2012; 76: 809-15. [Crossref]

15. Lavin JM, Smith C, Harris ZL, Thompson DM. Critical care resources utilized in high-risk adenotonsillectomy patients. $\mathrm{La}^{-}$ ryngoscope 2019; 129: 1229-34. [Crossref]

16. Kshirsagar R, Mahboubi H, Moriyama D, Ajose-Popoola O, Pham NS, Ahuja GS. Increased immediate postoperative hemorrhage in older and obese children after outpatient tonsillectomy. Int J Pediatr Otorhinolaryngol 2016; 84: 119-23. [Crossref]

17. Kou YF, Sakai M, Shah GB, Mitchell RB, Johnson RF. Postoperative respiratory complications and racial disparities following inpatient pediatric tonsillectomy: a cross-sectional study. Laryngoscope 2019; 129: 995-1000. [Crossref]

18. Lawlor CM, Riley CA, Carter JM, Rodriguez KH. Association between age and weight as risk factors for complication after tonsillectomy in healthy children. JAMA Otolaryngol Head Neck Surg 2018; 144: 399-405. [Crossref]

19. Venkatesan NN, Rodman RE, Mukerji SS. Post-tonsillectomy hemorrhage in children with hematological abnormalities. Int J Pediatr Otorhinolaryngol 2013; 77: 959-63. [Crossref]

20. Gehrke T, Scherzad A, Hagen R, Hackenberg S. Risk factors for children requiring adenotonsillectomy and their impact on postoperative complications: a retrospective analysis of 2000 patients. Anaesthesia 2019; 74: 1572-9. [Crossref]

21. Baugh RF, Archer SM, Mitchell RB, Rosenfeld RM, Amin R, Burns JJ, et al. Clinical practice guideline: tonsillectomy in children. Otolaryngol Head Neck Surg 2011; 144: S1-30. [Crossref]

22. Erickson BK, Larson DR, St Sauver JL, Meverden RA, Orvidas LJ. Changes in incidence and indications of tonsillectomy and adenotonsillectomy, 1970-2005. Otolaryngol Head Neck Surg 2009; 140: 894-901. [Crossref] 
23. Statham MM, Elluru RG, Buncher R, Kalra M. Adenotonsillectomy for obstructive sleep apnea syndrome in young children: prevalence of pulmonary complications. Arch Otolaryngol Head Neck Surg 2006; 132: 476-80. [Crossref]

24. Ikoma R, Sakane S, Niwa K, Kanetaka S, Kawano T, Oridate N. Risk factors for post-tonsillectomy hemorrhage. Auris Nasus Larynx 2014; 41: 376-9. [Crossref]

25. Vicini C, Eesa M, Hendawy E, Pari M, D'Agostino G, AlGhamdi $\mathrm{S}$, et al. Powered intracapsular tonsillotomy vs. conventional extracapsular tonsillectomy for pediatric OSA: a retrospective study about efficacy, complications and quality of life. Int J Pediatr Otorhinolaryngol 2015; 79: 1106-10. [Crossref]
26. Zhang LY, Zhong L, David M, Cervin A. Tonsillectomy or tonsillotomy? A systematic review for paediatric sleep-disordered breathing. Int J Pediatr Otorhinolaryngol 2017; 103: 4150. [Crossref]

27. Hultcrantz E, Ericsson E, Hemlin C, Hessén-Söderman AC, Roos K, Sunnergren O, et al. Paradigm shift in Sweden from tonsillectomy to tonsillotomy for children with upper airway obstructive symptoms due to tonsillar hypertrophy. Eur Arch Otorhinolaryngol 2013; 270: 2531-6. [Crossref]

28. Krishna P, Lee D. Post-tonsillectomy bleeding: a meta-analysis. Laryngoscope 2001; 111: 1358-61. [Crossref] 